\title{
Epidemiology of Adult Obesity, Measurements, Global Prevalence and Risk Factors
}

\author{
Udo Orukwowu \\ Department of Nursing Sciences, Faculty of Basic Medical Sciences, College of Medical Sciences, Rivers State University, \\ Nigeria.
}

Author email: udocd27@gmail.com; Phone: +2349060039098

\begin{abstract}
This report critically evaluated the epidemiology of obesity in adults. Epidemiology has been identified as an essential science in public health that enhances the strategies used to identify and map emerging diseases. The epidemiology of adult obesity is measured according to the rate of incidence, prevalence and mortality in a certain population through a number of variables including person, place and time. However, the incidence and prevalence of adult obesity have been discussed globally, nationally and regionally identifying places of increased incidence and prevalence in graphs, bar charts and tables. Significantly, public health practice has been indicated to underpin epidemiology studies which are useful to inform practice by providing different levels of intervention to curb adult obesity.
\end{abstract}

Keywords: Obesity, Adult obesity, Epidemiology of obesity, Risk factors of obesity, Prevalence

Cite as: Orukwowu, U. (2022). Epidemiology of Adult Obesity, Measurements, Global Prevalence and Risk Factors. IPS Intelligentsia Multidisciplinary Journal, 1(2), 1-6. https://doi.org/10.54117/iimj.v1i1.1.

\section{Introduction}

Obesity or overweight is referred to as the excessive or abnormal accumulation of fat that might present health risks in adults as classified in Table 1 (Wang et al., 2012). As a result, obesity or overweight in adults has been a major epidemic around the world (Brundi et al., 2012) and associated with severa comorbidities (Compos et al., 2006).

Table 1: Classification of obesity according to BMI level (BMI of Adults Age 20 and Older)

\begin{tabular}{ll}
\hline BMI & Classification \\
\hline 18.5 to 24.9 & Normal weight \\
25 to 29.9 & Overweight \\
$30+$ & Obesity \\
$40+$ & Extreme obesity \\
\hline
\end{tabular}

Source: NHANES, 2009-2010

Globally, obesity has been accorded one of the leading causes of death (Meacham and Vieira, 2012). According to Stewart (2010), obesity has caused several deaths worldwide which could have been prevented. As a result, studies have proven high blood pressure to cause $13 \%$ of death globally, $6 \%$ allocated to high blood glucose, $6 \%$ allocated to physical inactivity, and $5 \%$ allocated to obesity (WHO, 2012). According to World Health Organisation, $84 \%$ of the mortality risk occurs in countries of low and middle income (WHO, 2012). Conversely, Meacham and Vieira (2012), declared that the risk factor is majorly associated with countries of high income. It is alarming that statistic and trends have proven that over 2.8 million overweight and obese people die every year globally (Meacham and Vieira, 2012). This report critically evaluates the epidemiology of obesity in adults, with emphasis on epidemiological key concepts which includes incidence, prevalence, rates, ratios and risk. Essentially, the report will contribute to epidemiological information as relates its use in public health policy and practice.

\section{Epidemiology}

Epidemiology is an essential science in public health that is concerned with the determinants and distribution of diseases in a given population (Ben Shlomo et al., 2013). According to Compose et al. (2006), Epidemiology as a concept is an indispensable science in public health that enhances the strategies used to identify and map emerging diseases. However, an effective epidemiology approach depends on goal-directed and valid data collections (Spellman and Whiting, 2013). Tables 2 and 3 shows the various parameters used in epidemiology measurement.

\section{Mortality}

Recent study confirmed that obesity is a risk factor for increased rate of mortality in adults (Meacham and Vieira, 2012). According to Metha and Chang (2009), the increased rate of mortality has been attributed to complications arising from obesity (Fig. 1).

Table 2: Measurements in epidemiology

\begin{tabular}{|c|c|}
\hline $\begin{array}{l}\text { Incident, } \\
\text { Prevalence } \\
\text { and } \\
\text { Mortality } \\
\text { Rates }\end{array}$ & $\begin{array}{l}\text { Epidemiology is measured according to the rate of } \\
\text { incidence, prevalence and mortality in a certain population } \\
\text { through a number of variables (Stewart, 2010; Bailey and } \\
\text { Handu, 2013). McKenzie and Pinger (2013) proclaimed } \\
\text { that incidence and prevalence is measured by counting } \\
\text { cases in a specific population noted to be at risk of a disease } \\
\text { condition. Incidence and prevalence can be measured } \\
\text { against characteristics such as age, sex and race (Osborn, } \\
\text { 2006). Generally, Incidence and prevalence rates are } \\
\text { represented as below according to Osborn (2006); }\end{array}$ \\
\hline $\begin{array}{l}\text { Incident } \\
\text { Rate }\end{array}$ & $\begin{array}{l}\text { In incident rate, the numerator is the total number of new } \\
\text { cases of adult obesity in a specific period whereas the } \\
\text { denominator is total population at risk during this period as } \\
\text { represented below (Osborn, 2006). In calculating the } \\
\text { incidence rate, cases per } 10 \text { n and per day, per week, per } \\
\text { month, and per year must be included in the units of } \\
\text { incidence rate (Bonita } \text { et al., 2006) }\end{array}$ \\
\hline $\begin{array}{l}\text { Prevalence } \\
\text { Rate }\end{array}$ & $\begin{array}{l}\text { In prevalence, the numerator is referred to all new and pre- } \\
\text { existing cases of adult obesity in a specific period while the } \\
\text { denominator is the total population during the same time } \\
\text { period (Friis and Sellers, 2014). Essentially, the prevalence } \\
\text { rate is multiplied by } 10 \text { n which is the appropriate factor. As } \\
\text { a result, prevalence is usually expressed and presented as } \\
\text { cases per } 100 \text { or per } 1000 \text { population (Bonita et al., 2006). }\end{array}$ \\
\hline
\end{tabular}




$\begin{array}{ll}\text { Mortality } & \text { Mortality rate measures the number of deaths in a } \\ \text { Rate } & \text { population over a given period of time (Bailey and Handu, } \\ \text { 2013). Proportional mortality ration (PMR) is applied when } \\ \text { comparing age groups and the general population (Fletcher } \\ \text { and Fletcher, 2014). PMR refers to proportion of all death } \\ \text { occurring in a time interval due to a particular cause such as } \\ \text { adult obesity. It is expressed in percentage, with the sum of } \\ \text { the causes which is } 1.00(100 \%) \text { as below: }\end{array}$

\section{Incidence rate}

$=\frac{\text { Total number of new cases of adult obesity in a specific period }}{\text { Total population at }} \times 10^{n}$ Total population at risk during this period

(Bonita et al., 2006:18).

\section{Prevalence rate}

$=\frac{\text { All new and pre }- \text { existing cases of adult obesity in a specific period }}{\text { Total population during the same time period }} \times 10^{n}$

(Bonita et al., 2006:18)

\section{Mortality rate}

Number of deaths due to obesity during a given time interval

$=\frac{\text { Number of deaths from all causes in the same time interval }}{100}$

(Osborn, 2006)

Table 3: Characteristics of prevalence and incidence

\begin{tabular}{|c|c|c|}
\hline Characteristic & Incidence & Prevalence \\
\hline Numerator & $\begin{array}{l}\text { New cases occurring during a } \\
\text { period of time among a group } \\
\text { initially free of disease }\end{array}$ & $\begin{array}{l}\text { Existing cases at a } \\
\text { point or period of } \\
\text { time }\end{array}$ \\
\hline Denominator & $\begin{array}{l}\text { All susceptible people without } \\
\text { disease at the beginning of the } \\
\text { period }\end{array}$ & $\begin{array}{l}\text { All people examined, } \\
\text { including cases and } \\
\text { non-case }\end{array}$ \\
\hline Time & Duration of the period & Single point or period \\
\hline How measured & Cohort study & Cross-sectional study \\
\hline
\end{tabular}

Source: (Fletcher and Fletcher, 2014:19).

\section{Global, National and Local Perspectives}

Globally, obesity has been rising inevitably since 1980, it is still rising and causing adverse impacts on the health of the public (Friis and Sellers, 2014). According to World Health Organisation, it is a major health problem in developed nations and over 1.4 billion adults aged 20 and above were overweight in 2008, at the same time, 200 million men and over 300 million women were reported as obese. Therefore, $11 \%$ of adults aged 20 and above were obese while $35 \%$ were overweight respectively (WHO, 2012). Again, $35 \%$ of women and $34 \%$ of men were obese (WHO, 2008, WHO, 2012). By comparing the increase in prevalence since the year 1980 to $2008,14 \%$ of women and $10 \%$ of men were obese in 2008 compared to $8 \%$ of women and $5 \%$ of men in 1980. This has shown a great increase in the prevalence of obesity since 1980 worldwide according to statistical trends (WHO, 2012).

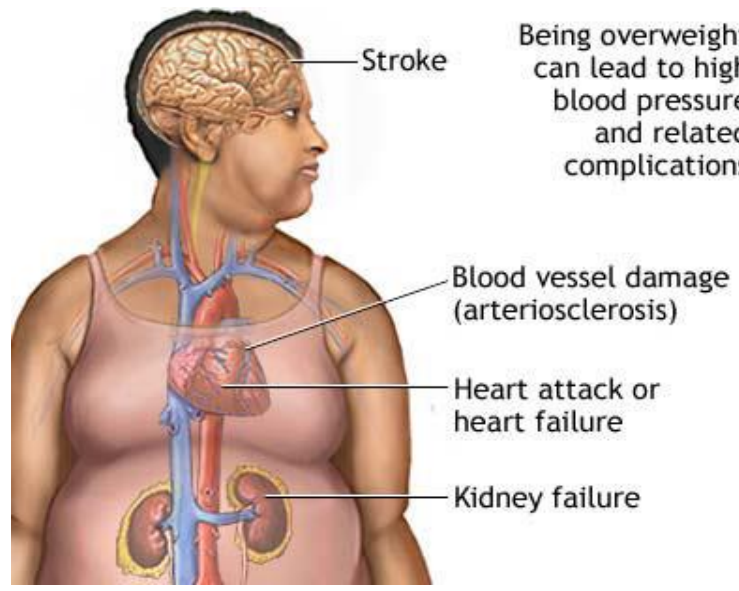

Figure 1: Secondary Complications of Obesity Leading to Death. Source: Newcastle Obesity Surgery Centre (2012).

Nevertheless, the accuracy of results on statistical trends depends on valid and reliable data collected in the local and regional settings. Although, a hundred per cent may not be achieved from records completeness and uniform methods in collecting epidemiological data. Therefore, the reliability of data is queried in some parts of the world due to the difficulties associated with data collection
(Oleske, 2009). Furthermore, difficulties associated with data collection have been attributed to poor quality of information; lack of good source of valid information; gaps and missing data; grossly inaccurate data; insecurity; systemic errors and bias: and lack of understanding of a whole community health status (Bendavid, 2011). Additionally, the economic status of a country has been established to affect data collection, low income countries have therefore been well-known to have difficulties in epidemiology data collection (WHO, 2012)

Nationally, adult obesity has also been attributed to a major problem in several countries both developed and developing (WHO, 2012). However, in Europe, UK has been noticed to be the highest in the prevalence of adult obesity. The National Obesity Observatory (NOO, 2013) data factsheet has shown in the above table that $36.9 \%$ of adults were overweight giving $41.4 \%$ of men and $32.5 \%$ of men whereas $24.8 \%$ were obese with $23.6 \%$ of men and $25.9 \%$ of females. However female had a higher prevalence in 2011. Consequently, between 2000/2001 to 2010/2011, a rise in hospital admission due to obesity as primary and secondary by gender was reported in England.

Locally, North East was reported to have the highest rate of incidence and prevalence of obesity in the UK with $13.1 \%$, seconded by North West and Yorkshire and Humbria having $11.5 \%$ and $11.3 \%$ respectively. Significantly, accurate data collection informs an effective epidemiology process. However, data collection in some part of the world may not be as accurate and reliable as it is in the UK or other western countries. Bendavid (2011:105) stated that "Collection of reliable statistical information depends upon the implementation of appropriate methodology" which will further enhance community diagnosis or situation analysis. Therefore, the lack of appropriate methods will make it difficult to collect data in some parts of the world.

\section{Person}

The epidemiology variable of a person is a major determinant of how obesity is distributed (Bailey and Handu, 2013). Epidemiology identifies persons that are affected as well as those not affected in the same place and at the same time (Friis and Sellers, 2014). This enables the provision of strong clues that enhances the need for health services to ascertain the cause and provide strategies to control factors that leads to developing obesity (Fletcher and Fletcher (2014). The epidemiological variable of person also leads to early hypothesis regarding the cause and how cases of adult obesity affects the persons identified (Bailey and Handu, 2013). However, the epidemiology variable of person is established by certain key determinants such as age, sex, physical activities, diet and socio economic status (Fletcher and Fletcher, 2014)

\subsection{Age and Gender}

Over the years, obesity has been a huge public health burden occurring in all ages (Friis and Sellers, 2014). In adults, weight and height are used to compute a person's BMI to measure or determine if he or she is overweight or obese (Meacham and Vieira, 2012). A global picture of obesity in both men and women aged 20 and above were depicted in figs 2 and 3.

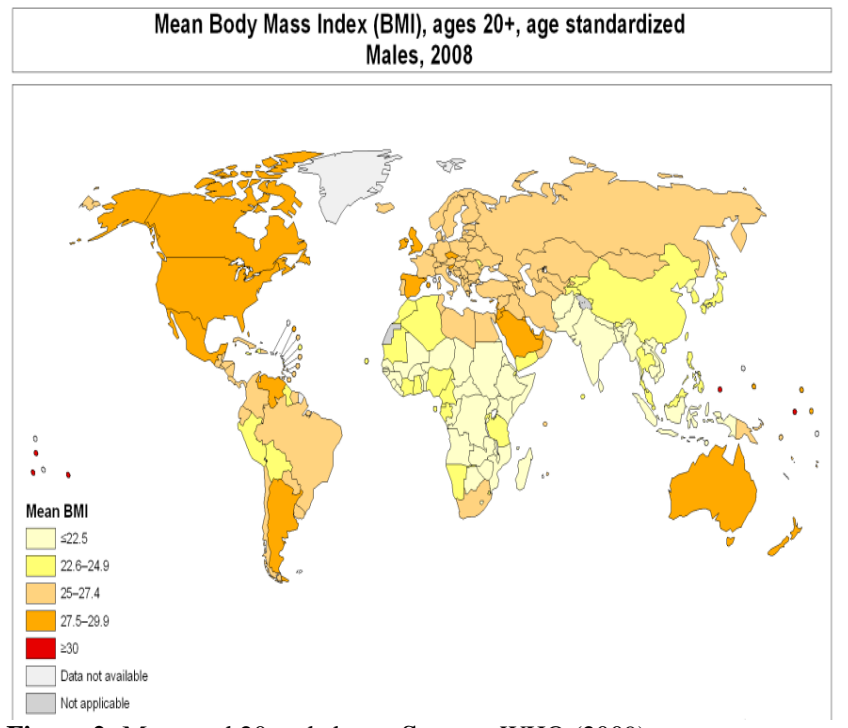

Figure 2: Men aged 20 and above. Source: WHO (2009). 


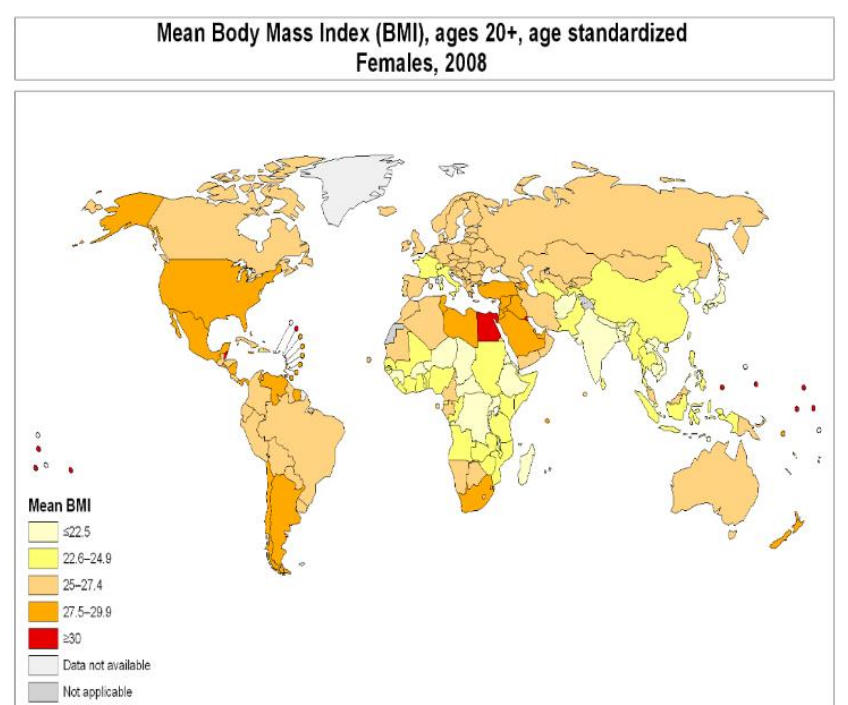

Figure 3: Women aged 20 and above. Source: WHO (2009).

Figure 4 shows standardized BMI of age in men and women aged 20 years and over, indicating increase in obesity future estimates. It shows that 1 billion people were estimated to be obese globally by 2008 , which will also increase up to 1.5 billion by 2015 (WHO, 2008).

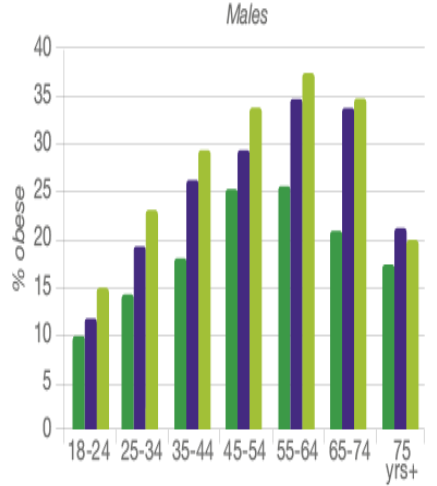

Age (years)

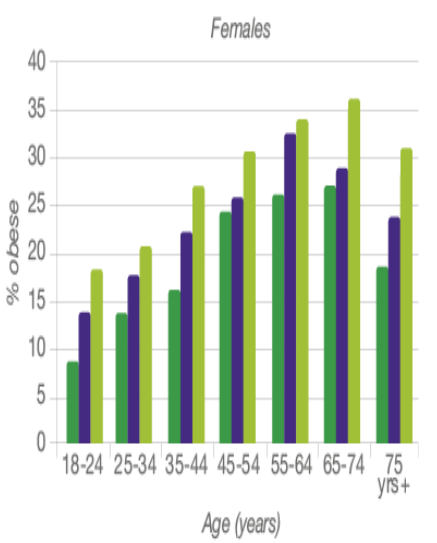

- $1995 \bullet 2007-08 \cdot 2011-12$
- $1995 \bullet 2007-08 \bullet 2011-12$

Figure 4: Prevalence of obesity by sex and age between 1995, 2007-2008 and 2011-2012. Source: State of Preventive Health (2013).

An increase in prevalence among women than men was reported (Ogben et $a l ., 2012)$. This has also been proven in several studies, indicating the increase in female adults getting more overweight and obese (Eastwood, 2013). According to Kopelman et al. (2009), the determinants that are responsible for the difference in trends in adult obesity for adults have been identified as changes in factors of lifestyle (Eastwood, 2013). These factors were identified as physical inactivity, increase in consuming unhealthy diet, increase alcoho intake (Ogben et al., 2012).

The determinants of obesity have also shown obesity in adults to result out of childhood obesity (Eastwood, 2013). Children that are overweight or obese have been reported to remain obese until adulthood or are prone to becoming obese in their adult life (Wahab et al., 2011). According to Ailshire (2011), this has been attributed to continual high-calorie intake as well as being inactive physically (Ogben et al., 2012). Most adult have also been reported to have the habit of a sedentary lifestyle leading to the accumulation of fat thereby becoming overweight or obese. However, Marcus (2013) emphatically argued that genetic factors could be a predisposing factor to that effect. On the other hand, low socioeconomic status has also been identified as a contributory factor to sustaining obesity (Wahab et al., 2011).

There is more prevalence of adult obesity in women has been identified in fig 5 especially in the first four countries which are the United States in 2008 , Mexico in 2006, Chile in 2004, New Zealand in 2007, Ireland in 2007 and United Kingdom in 2008. It has been noticed in fig 5 where some countries have a higher prevalence of obesity in men than women such as Luxembourg in 2007. Basically, fig 5 showed how obesity was distributed between men and women in the Organisation for Economic Co-operation and Development (OECD) countries.

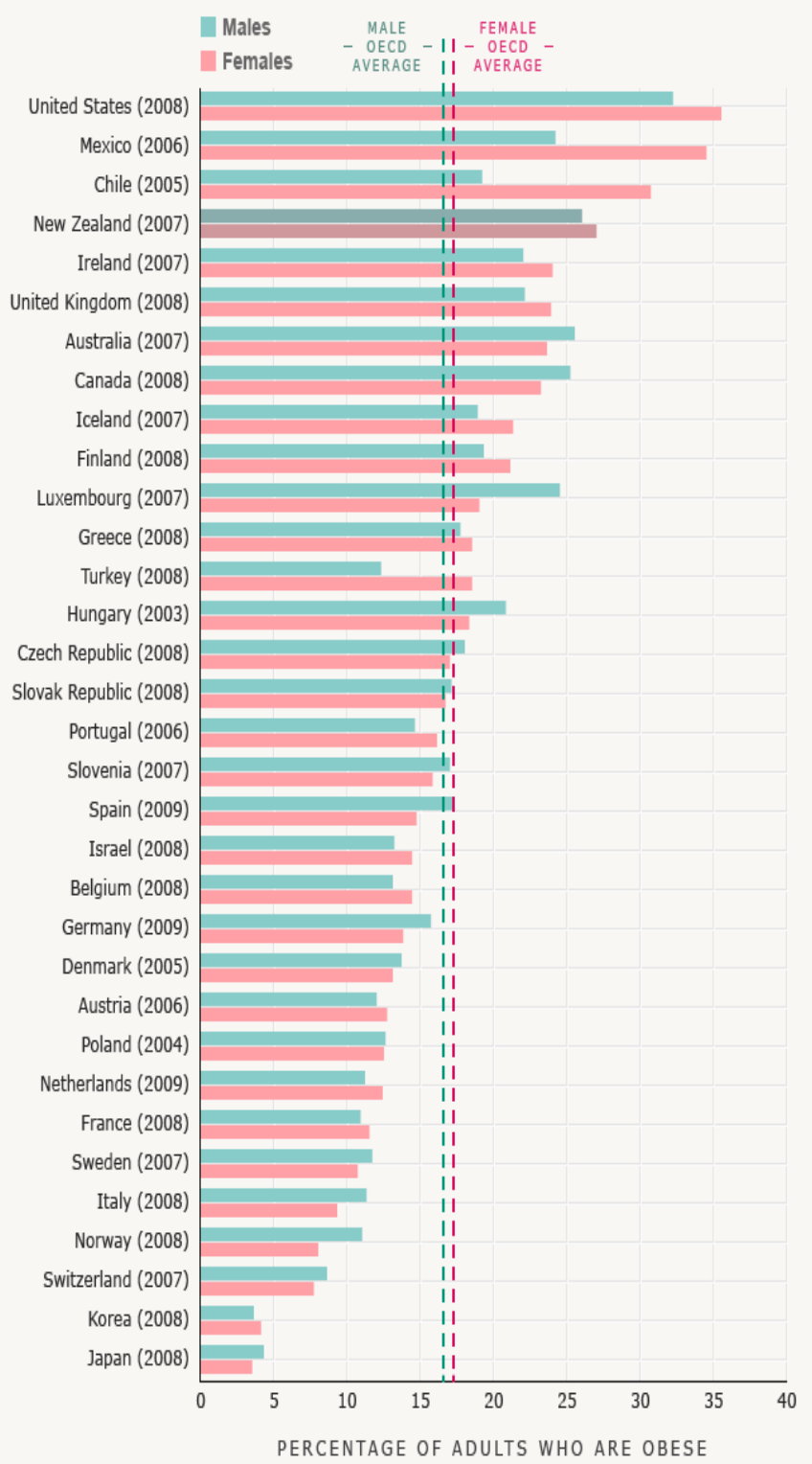

Figure 5: Percentage of obese adults (both men and women) in in OECD countries. Source: OECD (2012)

\subsection{Socioeconomic status}

According to McLaren (2007) several studies have proven the relationship between socioeconomic status and obesity worldwide. Friis and Sellers (2014) have also emphasized the increased prevalence of overweight and obesity affecting developing, industrial as well as transition economies around the globe affecting life expectancy (Eastwood, 2013). Significantly, the differences in socioeconomic status have increased the risk of obesity affecting individuals (Ball and Mishra, 2006).

Monteriro et al. (2004) carried out a study on the socioeconomic status and obesity populations of developing countries. This study was strategized to estimate the prevalence of obesity among adult populations. However, in the study, obesity was found more among the poor adults, more in women than men, due to economic development in both genders. This also reconciles with a more recent study that also reported increased prevalence of obesity among women than men (McLaren, 2009). Monteriro et al. (2004) accentuated that women had a more rapid prevalence of obesity occurring due to high health inequalities attributed to maternal and perinatal conditions, deficiencies in nutrition, and infectious diseases occurring among them. 
Inequalities occur as a result of disabilities, age, health, socioeconomic status (Klenke, 2008). Generally, obesity is closely related to social and economic deprivation which occurs mostly among those within the lowest income quintile (Bambra et al., 2012). Bambra et al. (2012) established that socioeconomic inequalities are embedded in gradient and as a result life course which has a close relation to obesity due to individuals' lifestyle. As a result, several studies have reported increased obesity due to socioeconomic inequalities (Ogben et al., 2012).

The National Obesity Observatory (NOO) (2012) data factsheet reported an increased prevalence of adult obesity due to socioeconomic status. The report revealed a high risk of obesity among women of lower socioeconomic status. However, women with high-income status had a low risk of obesity. Nevertheless, men of lower socioeconomic status have also been reported to be at risk of obesity. Education attainment, deprivation, social class, type of occupation, and level of household income have been seen as contributory factors to the risk of obesity (NOO, 2012).

\section{Place and Time}

Place and time are major key determinants of how cases of adult obesity are distributed geographically and the time of occurrence (Behan and Cox, 2010). However, in geographical distribution, the frequencies of occurrence of disease vary from time to time, one place to another (Metha and Chang, 2009). It also varies from one population group to the other in different times and locations (Bailey and Handu, 2013). Basically, the characteristics of place and time of occurrence of cases such as adult obesity include the incidence and prevalence in terms of global, regional, national and local places (Meacham and Vieira, 2012).

\section{Incidence and Prevalence \\ 7.1 Global Impact:}

Globally, adult obesity has impacted negatively to the health and economy of the population, with incidence and prevalence reaching and crossing projections (Shiromani et al., 2013). Several studies have shown a continued increase in adult obesity in different places as well as different times, indicating the places of highest prevalence (Klenke, 2008), where prediction has indicated that prevalence could reach $80 \%$ of the population having obesity (Ngunye et al., 2010). Figure 6 shows the global prevalence of obesity in adults.

The United States of America (USA) was reported to have the highest prevalence in obesity. However, currently, the highest prevalence of obesity is no longer in the United States of America (OECD Health Data, 2012). A Pacific Island called American Samoa with 700,000 populations in the 2013 census has been found to have the highest prevalence in obesity with $74.6 \%$ of the population being obese (Ngunyen et al., 2010). According to World Health Organisation, the reason for this increase in the prevalence of obesity in America Samoa has been attributed to cheap unhealthy fast food and a sedentary lifestyle (WHO, 2012).

However, the rates in the United States of America and Europe are reported to be generally high (Shiromani et al., 2013). Obesity has not only affected low and middle-income countries, it now affects high-income countries (Ogden $e t$ al., 2012). Moreover, obesity has also been attributed to be the problem of the western world (OECD Health Data, 2012). Male and female adults of different localities have been affected (Shiromani et al., 2013).

\subsection{National and local impacts}

Adult obesity has exerted a great health risk impact on the health of adults in different parts of the world (Fletcher and Fletcher, 2014). In the US over 35\% of women and men were found obese in the years 2009-2010. Epidemiology did not reveal any significant difference between the prevalence of obesity in US men and women at their different ages. However, more adults from 60 years and above had the likelihood of being more obese. Men had no significant difference by age but women aged 60 and above had $42.3 \%$ of obesity compared to women aged $20-39$ who had $31.9 \%$ (Ogden, 2012).

\section{Determinants}

Individuals are affected by the environment they were born, grew up, and work (Kleiser et al., 2009). They are also engulfed with other circumstances such as power level, income level and distribution of resources according to affordability (Monasta et al., 2010). Obesity has been found to affect people due to different factors in life such as urbanization (Rennie et al., 2005). However, several studies have claimed excessive intake of calories leads to obesity (Fletcher and Fletcher, 2014).
Rank

Country American Samoa Tokelau Tonga $\underline{\text { Kiribati }}$ $\underline{\text { Saudi Arabia }}$ United States United Arab Emirates Egypt Kuwait New Zealand Seychelles Fiii Mexico Canada Israel United Kingdom Greece Croatia Chile Bosnia and Herzegovina Malta

$\underline{\text { Lithuania }}$

Jordan

Poland

Hungary

France

Australia

Malaysia Peru

Turkey

Morocco

Zimbabwe

Finland

Spain

Latvia

Czech Republic

Slovenia

Estonia

Slovakia

Portugal

Iran

Colombia

Lebanon

Ireland

Germany

Bulgaria

Iceland

Sweden

$\underline{\text { Cuba }}$

Denmark

Brazil

Austria

Belgium

Norway

Mongolia

Italy

Romania

Switzerland

Thailand

Singapore

Philippines

62 Eritrea
Obesity - adult prevalence rate $(\%)$

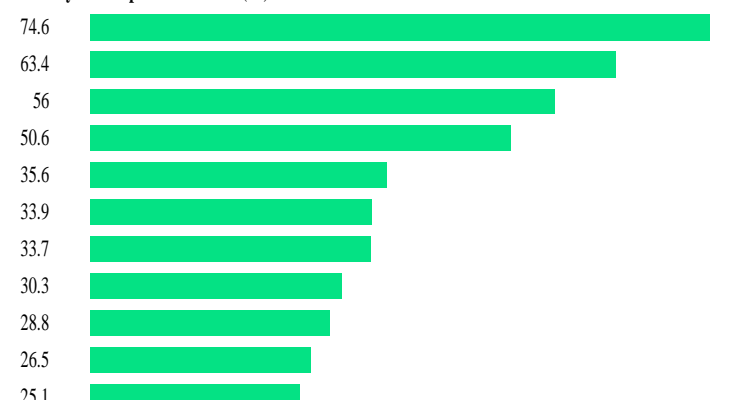

25.1

23.9

23.6

23.1

22.9

22.7

22.5

22.3
21.9

21.7

20.7

19.7

19.5

18

17.7

16.9

16.9
16.4

16.3
16.3

16.3

16.1

16

15.7
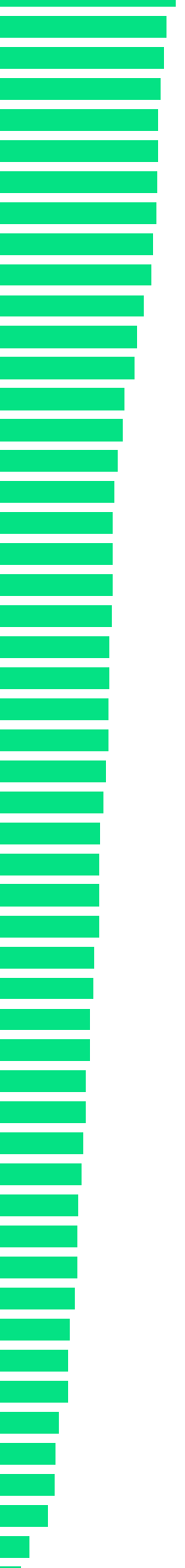

Figure 6: Prevalence of adult obesity by country rates. Showing the current and recent country having the highest prevalence of obesity which is America Samoa (74.6\%). Source: OECD Health Data 2012 
According to Dahlgren and Whitehead (1991) model (Fig. 7), different factors can affect people and lead to disease conditions such as obesity. These factors include cultural and environmental factors, socioeconomic conditions, age and sex factors, social and community factors and the lifestyle of an individual According to Monasta et al. (2010), the levels indicated in the socia determinants of health are interconnected.

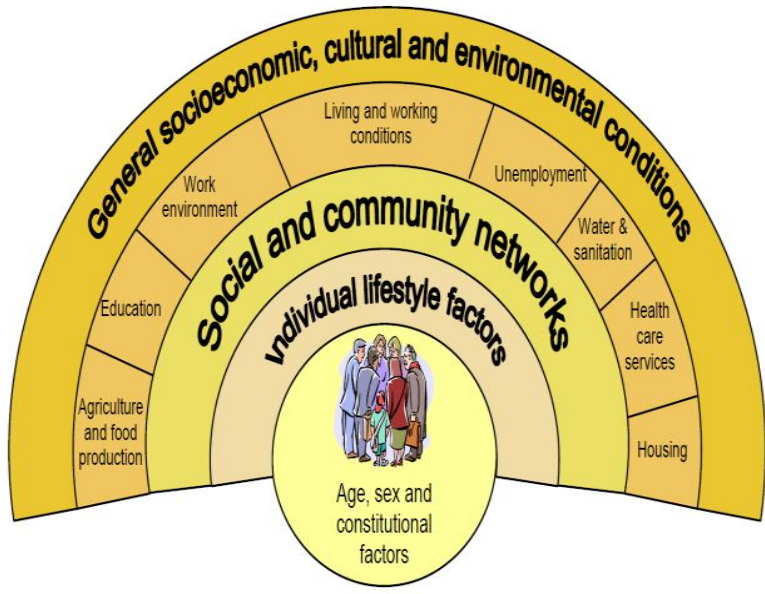

Figure 7: Social Model of Health - Dahlgren and Whitehead (1991) Model.

Nevertheless, level of education, housing status, unemployment, living and working conditions, inability to access healthcare services, lack of health advice have been attributed to sustaining diseases such as obesity (Dahlgren and Whitehead, 1991). According to Cox (2010) the above mention factors could result in not being able to purchase or eat the right food or not living a good lifestyle thereby leading to having obesity.

\section{Risk Factors}

According to Ngunyen and El-serag (2012) a number of risk factors to obesity or overweight have been identified (Table 4); these risk factors include genetics, inactivity, unhealthy diet and eating habit, family lifestyle, quitting smoking, pregnancy, certain medication, age, social and economic issues and medical problems. Generally, the social determinants of health are engulfed in the risk factors which affect the person, place and time. (Fletcher and Fletcher, 2014).

Table 4: Example of decrease and increase risk of developing obesity.

\begin{tabular}{l|ll}
\hline & Decreases Risk & Increases Risk \\
\hline Convincing & Physical activity & Sedentary living \\
Probable & Low energy-dense & Energy-dense foods \\
& foods. & Sugary drings. \\
& Being breastfed & Fast foods. \\
& & Television viewing \\
\hline
\end{tabular}

According to Kleiser et al. (2009), the lifestyle of an individual contributes immensely to developing obesity. In the above table, the people that develop obesity are those that eat unhealthy food and those that do not engage in active physical activities as in American Samoa making them have the highes prevalence of obesity worldwide (WHO, 2012; Ngunyen and El-serag, 2012). Consequently, the risk of developing obesity could lead an individual to develop the relative risks as indicated in Table 5.

Table 5: Relative risks associated with obesity.

\begin{tabular}{lll}
\hline $\begin{array}{l}\text { Relative risk } \\
\text { greater than 3 }\end{array}$ & Relative risk 2-3 & Relative risk 1-2 \\
\hline Type 2 diabetes & $\begin{array}{l}\text { Coronary heart } \\
\text { disease } \\
\text { Hypertension }\end{array}$ & Cancer \\
Dyslipidaemia & $\begin{array}{l}\text { Osteoarthritis } \\
\text { (knees) }\end{array}$ & $\begin{array}{l}\text { Pobnormalities } \\
\text { Polycystic ovary syndrome }\end{array}$ \\
Insulin resistance & $\begin{array}{l}\text { Hyperuriceamia } \\
\text { and gout }\end{array}$ & Impaired fertility \\
$\begin{array}{l}\text { Breathlessness } \\
\text { Sleep apnoea }\end{array}$ & $\begin{array}{l}\text { Low back pain } \\
\text { Increased risk of } \\
\text { anaesthesia complications }\end{array}$ \\
& & $\begin{array}{l}\text { Fetal defects (associated } \\
\text { with maternal obesity). }\end{array}$ \\
\hline
\end{tabular}

\section{Life Expectancy}

Obesity has been identified as a source of lowering life expectancy (Waldron, 2007; Bleich et al., 2009). 40 years of age is the estimated life expectancy of an obese individual (Alley et al., 2010). However, it has been established that people classified as obese are expected to leave six to seven years lesser than those defined to have a normal weight (Glei et al., 2010). The reduced life expectancy of obese people has been associated with the risks from obesity as in the above table.

\section{Application to Practice/Public Health Interventions}

Spellman and Whiting (2013) emphasised that epidemiology underpins public health as a key quantitative discipline that reveals the causes of illnesses. Generally, public health organisations are designed to provide diverse epidemiological investigations of diseases and conditions such as obesity (Killewo et al., 2010; Somerville, 2012). Consequently, solutions to the outcome of their investigations are disseminated to stop or reduce a particular cause (Adams et al., 2010). In terms of obesity, to reduce preventable deaths and its adverse impacts, different levels of interventions have been applied as methods, strategies, policies to improve the health of the public (Bonita et al. 2006; Adams et al., 2010) as in Table 6.

\begin{tabular}{ll}
\hline \multicolumn{2}{c}{ Table 6: } \\
\hline Strategies and & $\begin{array}{l}\text { Strategies, } \\
\text { Methods } \\
\text { and Policies }\end{array}$ \\
\hline $\mathbf{1}$ & $\begin{array}{l}\text { Joint } \\
\text { Strategic } \\
\text { Needs } \\
\text { Assessment }\end{array}$ \\
& \\
\hline $\mathbf{2}$ & $\begin{array}{l}\text { Care } \\
\text { Pathway }\end{array}$ \\
\hline
\end{tabular}

licies used to prevent and manage obesity

\section{Interventions, Rationales and Benefits}

Joint Strategic Needs Assessment is a strategy developed to enhance the public to achieve a healthy weight. This strategy was divided into five tiers. Tier 1 was based on provision of health advice from health provisional through media adverts, in schools, in policies as well as influencers consisting of town planner, transport, and preventable measures in food policy. Tier 2 weight management based on community programmes. Tier 3 was weight management based on referral programmes for exercise and dietetic appointments. Tier 4 was based on multidisciplinary specialist weight management in the hospital and tier 5 was based on high cost intervention such as surgery (French et al., 2011).

Care pathway was designed for overweight and obesity management among adults starting with assessment and history of the client consisting social, medical, physical activity, dietary histories to inform management. Consequently, a line of management will be established which comprises healthy eating, reduced calorie intake, increased physical exercise, a change in behaviour and lifestyle. Medical and surgical treatment will be given to extreme cases, then maintenance and monitoring programmes will be initiated (DoH, 2006; French et al., 2011). $\begin{array}{lll}\text { Involving } & \text { Partnership with health trainers and local authorities } \\ \text { local } & \text { will facilitate the provision of safety physical and }\end{array}$ authorities health activities through schemes, facilities, spaces and health for physical activities, safer routes for walk and trainers cycling (DiMaggio, 2012).

4 Involving Workplaces, schools and universities are involved work places, regarding healthy lifestyle. They encourage increased schools and physical activities, healthy choice of eating through universities Food Standard Agency (FSA) Guidance. They encourage active travelling, social activities for recreations, local facilities to enhance leisures (Summerfield, 2012).

\begin{tabular}{lll}
5 & $\begin{array}{l}\text { Partnership } \\
\text { with } \\
\text { organisation } \\
\mathrm{s} \text { and local } \\
\text { authorities }\end{array}$ & $\begin{array}{l}\text { Partnership with organisations and local authorities } \\
\text { regarding behavioural factors and lifestyle. This will } \\
\text { ensure adequate obesity related information } \\
\text { dissemination, emphasizing on the benefit of healthy } \\
\text { lifestyle and behaviour. Also ensures the adequate } \\
\text { provision of counselling (DiMaggio, 2012). }\end{array}$ \\
$\mathbf{6}$ & $\begin{array}{l}\text { Equality } \\
\text { Impact } \\
\text { Assessment } \\
\text { (EIA). }\end{array}$ & $\begin{array}{l}\text { address issues regarding deprivations, inequalities, } \\
\text { socioeconomic status, lack of access to health } \\
\text { facilities and poverty to reduce the prevalence of } \\
\text { obesity and improve health of the public (French et } \\
\text { al., 2011). }\end{array}$ \\
\hline
\end{tabular}

\section{Conclusion and Recommendations}

Governmental and nongovernmental organisations have jointly provided several cost-effective and evidence based strategies, integrating both clinical 
and preventive public health interventions in the management of obesity. This is necessary to enhance the concept of utilitarianism to uphold the health for all concepts, to avoid preventable deaths and reduce the increased incidence and prevalence of obesity. Therefore, it is recommended that further studies should be carried out on the incidence and prevalence of obesity and how public practice has been used to inform epidemiology practice to promote health.

\section{References}

Australian National Preventive Health Agency (ANPHA). State of Preventive Health 2013. Report to the Australian Government Minister for Health. Canberra; ANPHA, 2013

http://anpha.gov.au/internet/anpha/publishing.nsf/Content/state-of-prevhealth-2013

Bailey, S. L. and Handu, D. (2013). Introduction to epidemiological research methods in public health practice. Burlington. Jones and Bartlett Learning.

Ball, K. and Mishra, G. D. (2006). Whos socioeconomic status influences a women's obesity risk: her mother's, her father's or her own? International Journal of Epidemiology, Vol. 35, Pg. 131-138.

Bambra, C. L., Hiller, F. C., Moore, H. J. and Summerbell, C. D. (2012). Tackling inequalities in obesity: a protocol for a systematic review of the effectiveness of public health interventions at reducing socioeconomic inequalities in obesity amongst children. Systematic Reviews, Vol. 1, Iss. 16, Pp. 1-7.

Bassett, C. and Bassett, J. (2003). Reading and critiquing research. British journal of perioperative nursing, Vol. 13, Iss. 4, Pp. 162-164.

Behan, D. F. and Cox, S. H. (2010). Obesity and its relation to mortality and morbidity costs. Manitoba. Society of Actuaries.

Ben-Shlomo, Y., Brookes, S. T. and Hickman, M. (2013). Lecture notes: Epidemiology, evidence-based medicine and public health. $6^{\text {th }}$ Edition. London. Wiley-Blackwell.

Bendavid, R. (2011). Abdominal Wall Hernias: Principles and Management. New York. Springer.

Biehl, A., Hovengen, R., Meyer, H. E., Hjelmesaeth, J., Meisfjord, J., Groholt, E. Roelants, M. Strand, B. H. (2013). Impact of instrument error on the estimated prevalence of overweight and obesity in population-based survey. BMC Public Health, Vol. 13, Pg. 146.

Bleich, S., Cutler, D., Murray, C. and Adams, A. (2008). Why is the developed world obese? Annual Review of Public Health, Vol. 29, Pp. 273-295.

Bonita, R., Beaglehole, R. and Kjellstrom, T. (2006). Basic Epidemiology. $2^{\text {nd }}$ Edition. Geneva. WHO Press.

Conkin Dale, J. (2005). Critiquing research for use in practice. Journal of Paediatric Health Care, Vol. 19, Pp. 183-186.

Coughlan, M., Cronin, P. and Ryan, F. (2007). Step-by-step to critiquing research Part 1: quantitative research. British Journal of Nursing, Vol. 16, Iss. 11, Pp. 658-663.

Dave, D. M., Tennant, J. and Colman, G. J. (2011). Isolating the effect of major depression on obesity: Role of selection bias. http://www.nber.org/papers/w17068 (Accessed 24/12/2013).

Delgado, M. (2013).Social Justice and the Urban Obesity Crisis: Implications for Social Work. New York. Columbia University Press.

Department of Health (2006). Care pathway for the management of overweight and obesity. London. Stationary Office.

Department of Health (2009). Care pathway for the management of overweight and obesity. London. Stationary Office.

DiMaggio, C. (2012). SAS for epidemiologist: Applications and methods. New York. Springer.

DoH (2012). Facts and figures on obesity. London. Stationary Office.

Dovey, T. M. (2010). Eating behaviour. Berkshire. Open University Press.

Eastwood, P. (2013). Health and social care information centre is England's central, authoritative source of health and social care information. England. The Health and Information Centre. www.ic.nhs.uk (Accessed 16/12/2013).

Fletcher, W. and Fletcher, G. S. (2014). Clinical epidemiology: The essentials. 5th Edition. Philadelphia. Lippincott Williams and Wilkins.

French, V., Nichols, J. and Rundle, S. (2011). Obesity / Achieving Healthy Weight: Joint strategic needs assessment. http://www.sunderland.gov.uk/CHttpHandler.ashx? $\mathrm{id}=12161 \& \mathrm{p}=0$ (Accessed 10/02/2013).

Friis, R. H. and Sellers, T. A. (2014). Epidemiology for public health. $5^{\text {th }}$ Edition Burlington. Jones and Bartlett Learning.

Gerstman, B. B. (2013). Epidemiology kept simple: An introduction to traditional and modern epidemiology. 3rd Edition. London. Wiley-Blackwell.
Glei, D. A., Mesle, F. and Vallin, J. (2010). Diverging trends in life expectancy at age 40: A look at cause of death. National Research Council, Vol. 1, Pp. 17 67.

Ha, P. L. and Baurain, B. (2011). Voices, identities, negotiations, and conflicts: Writing academic English across cultures. Bingley. Emerald Group Publishing Limited.

Himes, J. H. (2009). Challenges of accurately measuring and using BMI and other indicators of obesity in children. Paediatrics, Vol. 124, Iss. 1, Pp. 3-22.

Kelly, T., Yang, W., Chen, C. S., Reynolds, K. and He, J. (2008). Global burden of obesity in 2005 and projections to 2030. International Journal of Obesity, Vol. 32, Pp. 1431-1437.

Killewo, J., Heggenhougen, H. K. and Quah, S. R. (2010). Epidemiology and demography in public health. London. Elsevier.

Kleiser, C., Rosario, A. S., Mensink, G. B. M., Prinz-Langenohl, R. and Kurth, B. (2009). Potential determinants of obesity among children and adolescents in Germany: results from the cross-sectional KiGGS study. BMC Public Health, Vol. 9. Iss. 46, Pp. 1-14.

McKenzie, J. F. and Pinger, R. R. (2013). An Introduction to Community Health Brief Edition. Burlington. Jones and Bartlett Learning.

McLaren, L. (2007). Socioeconomic status and obesity. Epidemiologic Review, Vol. 29, Pp. 29-48

Meacham, R. and Vieira, F. (2012). Is obesity truly a risk factor for mortality after tracheostomy. Anals of Otology, Rhinology and Laryngology, Vol. 12 Iss. 11, Pp. 733-737.

Metha, N. and Chang, V. W. (2009). Mortality attributed to obesity among middle-age adults in the United States. Demography, Vol. 46, Iss. 4, Pp 851-872.

Monasta, L., Batty, G. D., Cattaneo, A., Lutje, V., Ronfani, L., Van Lenthe, F. J. and Brug, J. (2010). Early-life determinants of overweight and obesity: a review of systematic reviews. Obesity Review, Vol. 10, Pp. 695-708.

Monsen, E. R. (2008). Research: Successful approaches. 3rd Edition. New York. American Dietetic Association.

Monteriro, C.A., Moura, E. C., Conde, W.L. and Popkin, B. M. (2004). Socioeconomic status and obesity in adult populations of developing countries: a review. Bulletin of the World Health Organisation, Vol. 82, Pp 940-946.

National Obesity Observatory Data Factsheet (2012). Adult obesity and socioeconomic status. www.noo.org.uk. (Accessed 16/12/2013).

Newman, A. B. and Cauley, J. A. (2008). The epidemiology of aging. London. Springer.

Ogben, C. L., Carroll, M. D. and Kit, B. K. (2012). Prevalence of Obesity in the United States, 2009-2010. NCHS Data Brief, Iss. 82, Pp. 1-8.

Osborn, C. E. (2006). Statistical applications for health information management. 2nd Edition. London. Jones and Bartlett Publishers.

Pilot, D. ad Beck, C. (2006). Essentials of nursing care, appraisal and utilization. $6^{\text {th }}$ Edition. Philadelphia. Lippincott Wilkins.

Rennie, K. L., Johnson, L. and Jebb, S. A. (2005). Behavioural determinants of obesity. Best Practice and research. Clinical Endocrinology and Metabolism, Vol. 19, Iss. 3, Pp. 343-358.

Rothman, K. J. (2008). BMI-related errors in measurement of obesity. International Journal of Obesity, Vol. 32, Iss. 3, Pp. 56-59.

Shiromani, P. J., Horvath, T., Redline S. and Cauter, E. V. (2013). Sleep loss and obesity: intersecting epidemics. New York. Springer.

Somerville, M., Kumaran, K. and Anderson. (2012). Public health and epidemiology at a glance. Oxford. Wiley-Blackwell

Spellman, F. R. and Whiting, N. E. (2013). Handbook of Mathematics and Statistics for the Environment. Florida. CRC Press.

Stewart, A. (2010). Basic Statistics and epidemiology: A practical guide. $3^{\text {rd }}$ Edition. Oxon. Radcliffe Publishing Limited.

Summerfield, L. M. (2012). Nutrition, Exercise, and Behaviour: An Integrated Approach to Weight Management. $2^{\text {nd }}$ Edition. Belmont. Wadsworth.

Wahab, K. W., Sani, M. U., Yusuf, B. O., Gbadamosi, M., Gbadamosi, A. and Yandutse, M. I. (2011). Prevalence and determinants of obesity - a crosssectional study of an adult Northern Nigerian Population. International Archives of Medicine, Vol. 4, Iss. 10, Pp. 1-5.

Waldron, H. (2007). Trends in mortality differential and life expectancy for male social security-covered workers, by socioeconomic status. Social Security Bulletin, Vol. 67, Iss. 3, Pp. 1-28.

Williamson, J. (2011). Healthy vessels: A Christian guide for a healthy lifestyle. Bloomington. iUniverse.

Xiao, Y., Zhao, N., Wang, H., Zhang, J., He, Q., Su, D., Zhao, M., Wang, L., Zhang, X., Gong, W., Hu, R., Yu, M., Ding, G., Cong, L. and Ye, Z. (2013). Association between socioeconomic status and obesity in a Chinese adult population. BMC Public Health, Vol. 13, Pg. 355

Thank you for publishing with us. 